\title{
Technical efficiency of teaching hospitals in Iran: the use of Stochastic Frontier Analysis, 1999-2011
}

\author{
Reza Goudarzi ${ }^{1}$, Abolghasem Pourreza ${ }^{1}$, Mostafa Shokoohi ${ }^{2, *}$, Roohollah Askari $^{1}$, Mahdi Mahdavi ${ }^{3}$, Javad Moghri $^{1}$
}

Abstract

Background: Hospitals are highly resource-dependent settings, which spend a large proportion of healthcare financial resources. The analysis of hospital efficiency can provide insight into how scarce resources are used to create health values. This study examines the Technical Efficiency (TE) of 12 teaching hospitals affiliated with Tehran University of Medical Sciences (TUMS) between 1999 and 2011.

Methods: The Stochastic Frontier Analysis (SFA) method was applied to estimate the efficiency of TUMS hospitals. A best function, referred to as output and input parameters, was calculated for the hospitals. Number of medical doctors, nurses, and other personnel, active beds, and outpatient admissions were considered as the input variables and number of inpatient admissions as an output variable.

Results: The mean level of TE was 59\% (ranging from 22 to 81\%). During the study period the efficiency increased from 61 to $71 \%$. Outpatient admission, other personnel and medical doctors significantly and positively affected the production $(P<0.05)$. Concerning the Constant Return to Scale (CRS), an optimal production scale was found, implying that the productions of the hospitals were approximately constant. Conclusion: Findings of this study show a remarkable waste of resources in the TUMS hospital during the decade considered. This warrants policy-makers and top management in TUMS to consider steps to improve the financial management of the university hospitals.

Keywords: Hospital, Stochastic Frontier Analysis (SFA), Technical Efficiency (TE), Iran

Copyright: @ 2014 by Kerman University of Medical Sciences

Citation: Goudarzi R, Pourreza A, Shokoohi M, Askari R, Mahdavi M, Moghri J. Technical efficiency of teaching hospitals in Iran: the use of Stochastic Frontier Analysis, 1999-2011. Int J Health Policy Manag 2014; 3: 91-97. doi: 10.15171/ijhpm.2014.66
Article History: Received: 14 April 2014 Accepted: 21 July 2014 ePublished: 26 July 2014

*Correspondence to: Mostafa Shokoohi

Email: shokouhi.mostafa@gmail.com

\section{Introduction}

Hospitals are the leading costly units among health service delivery settings, which consume a large proportion of limited financial resources (1). Inefficient use of resources in hospitals is particularly common in the developing countries. Iran makes no exception $(2,3)$. Escalating healthcare expenditures triggers cost crisis in developing nations. This poses various challenges in resource allocation and budgeting $(4,5)$.

On the demand side, patient expectations, demographic characteristics, and disease models have changed. Patients seek quality services with the highest effectiveness. Populations are aging and diseases are transforming from communicable diseases to chronic diseases. These phenomena upscale the burden of diseases and subsequent demand and cost crisis. On the other hand, inefficient use of resources in hospitals limits the provision of health service to populations, in turn leading to an increased unmet demands and worsening cost crisis $(6,7)$. Given these challenges, the impetus for improving the efficiency of hospitals has been amplified. In order to give insight into value in terms of health service outputs that can be obtained by available resources, various studies assess Technical Efficiency (TE) of hospitals.

TE is defined as the relationship between outputs (measured in terms of both quantity and quality such as monetary terms) and inputs (the resources used to produce heath outputs such as patient care). In a simple term, an efficient
Decision Making Units (DMUs) produces a given amount of outputs using a lower amount of inputs than it used to do, or produces a higher amount of outputs using a given amount of inputs (8). The lack of TE may result from poor management of resources such as the use of specialists for activities that can be performed by nurses, inappropriate use of medical equipment, and/or a lack of productivity (9-12).

Multiple studies have used the Data Envelopment Analysis (DEA) and Stochastic Frontier Analysis (SFA) methods to assess the TE of hospitals in the developed (13-15) and developing countries $(16,17)$. Only few studies are conducted using the SFA regardless of the country studied $(18,19)$. Studies on the efficiency analysis of hospitals in Iran, in line with studies in other countries, mostly rely on the DEA method. A review by Kiadaliri et al. (18) on hospital efficiency in Iran reveals that DEA is the dominant method for hospital efficiency analysis. They report that out of 43 studies, a large majority has used DEA methods. They found that studies based on DEA report a higher efficiency score than studies applying SFA. Evidence of these studies advances understandings on the productivity of hospitals and hospital expenses in Iranian hospitals (18). However, few studies have discussed research implications of findings based on the DEA method for the hospital efficiency (20-22). Researchers apply this method thanks to its simplicity in dealing with input and output variables. 
Other researchers consider variables that are taken into consideration in efficiency analysis. Afzali et al. proposed a generic conceptual framework to capture suitable (conventional and non-conventional) variables of hospital structure, throughputs, outputs, and outcomes for TE analysis of general hospitals in Iran (2). They also reported factors that impact efficiency of hospitals. Afzali et al. found that organizational factors, skill and expertise of hospital managers, and remedial practices affect hospital efficiency in the Iranian Social Security Organization (SSO) (23).

The main objective of the present study is to measure the TE of teaching hospitals affiliated with Tehran University of Medical Sciences (TUMS), in Tehran, Iran. This study uses SFA to assess changes in the efficiency of hospitals over 13 years from 1999 to 2011 .

\section{Materials and methods}

In this descriptive cross-sectional study, necessary statistics of 12 teaching hospitals affiliated with TUMS were selected. Data was gathered from the Annual Statistical Report published by the statistical center of TUMS from April 1999 to March 2011. The report consisted of administrative and operational information for each TUMS's hospitals. Information was obtained from all hospitals. Data using methods of observation, interview, and an assessment of the documents, sources, records, and statistics of all target hospitals were collected from 1999 to 2011.

\section{Stochastic Frontier Analysis vs. Data Envelopment Analysis} DEA and SFA are two types of mathematical programming techniques to calculate the efficiency and productivity. These methods enable comparisons between efficiency versus an estimated efficient frontier. SFA is a parametric method based on the principle of econometrics and the theories of the micro-econometrics that uses a panel data to estimate a production (cost) function based on known hypotheses or statistical estimations. In contrast, DEA is a non-parametric deterministic method which estimates efficiency based on multiple productivities. An effective frontier curve by DEA is made up by linking a series of points that are determined by a linear programming (24-28). DEA, unlike the SFA, requires only input and output variables.

An advantage of SFA is the ability to diagnose Latent heterogeneities among DMUs. This allows distinction to be made between effects caused by an inefficiency and/or statistical errors. Whereas, DEA makes no distinction between effects caused by inefficiency and an outlier or measurement error and attributes all these effects to inefficiency $(29,30)$. Given these methodological concerns (31), the present study relies on SFA. The SFA is estimated by two methods of Maximum Likelihood Estimation (MLE), and/or Ordinary Least Square (OLS) in panel data (32). We can also perform the statistical significance using this method.

\section{Input and output variables}

Five input variables $\left(\mathrm{x}_{\mathrm{i}}\right)$ were addressed (2) in this research: 1) the number of Full Time Equivalent (FTE) physicians, 2) the number of FTE practicing nurses, 3) the number of
FTE other personnel, 4) the number of the active beds, and 5) the number of outpatient admission (the number of both outpatient visits and emergency visits were considered as "outpatient admission"). The categorization of the staff to three categories of physicians, nurses, and other personnel was due to the evidence that these categories of resources have different roles in patient care and deliver services with different levels of quality and patient satisfaction. Output variables (y) were the number of inpatient admission, the number of surgical operations, and the average length of stay for patients $(33,34)$.

\section{Modelling}

In the modeling, we first presented a general mathematical formula for SFA and then tailored it to the purpose of the current study. Both production and cost functions can be estimated using SFA. In this study, we only estimated production function. A Total Production (TP) of a hospital (or hospital output) can be estimated as follows (Equation 1):

$$
T P_{i}=f\left(L_{i}, K_{i}\right)+e_{i}
$$

Where TP represents the total production, $L$ is a vector of human resources and $K$ is a vector of capital resources. This technique is a regression model that can be specified as the following (Equation 2):

$$
Y_{i}=a+X_{i} \beta+e_{i}
$$

Where $Y$ represents the $T P_{i}$ (or final hospital output), and $X$ represents the $L$ and $K$ (or inputs), the final parameter is $e$ that represents errors decomposed as follows (Equation 3):

$e_{i}=v_{i}+u_{i}$

Where $v$ is a random error term which is normally distributed and is uncorrelated with the explanatory variables and $u$ represents the hospital specific fixed effects or time invariant production inefficiency. It is suggested that when panel data is available, there is no need to specify a particular distribution for inefficiency effects, and the measures of TE are relatively obtained from the most efficient hospital (35).

In general, following Schmidt (35), the model is specified as Equation 4:

$Y_{i t}=a+X_{i t} \beta+\left(V_{i t}-U_{i t}\right)$

where $Y_{i t}$ is the output for hospital, $i$ in time, $t$ and $X_{j i t}$ are vectors of inputs, and $U_{i t}$ represents hospital specific fixed effects or time invariant TE and $V_{i t}$ is a normally distributed random error term and is uncorrelated with the explanatory variables. To apply model 2 into our data, we needed to specify an appropriate functional form for the production of the hospital outputs. Two functional forms, the Cobb-Douglas and Translog functional, have been specified by previous studies. Gannon estimated both the Cobb-Douglas and Translog functional forms and then tested the null hypothesis. He found that the Cobb-Douglas form is an adequate representation of 
the data (36). The Cobb-Douglas form is also found to be an adequate representation in other studies (37). We, therefore, followed a similar approach and used both forms. The CobbDouglas function form is as follows (Equation 5):

$$
\operatorname{Ln} Y_{i t}=\beta_{0}+\sum \beta_{j} X_{j i t}+\left(V_{i t}-U_{i t}\right)
$$

And Translog function form as Equation 6:

$$
L n Y_{i t}=\beta_{0}+\sum \beta_{j} X_{j i t}+\sum \sum \beta_{j k} X_{j i t} X_{k i t}+\left(V_{i t}-U_{i t}\right)
$$

To select a proper function for the estimation of the efficiency, the Likelihood-Ratio (LR) test was used. The general form is as follows (Equation 7):

$\mathrm{LR}=$ Likelihood Ratio $=-2\{\mathrm{Ln}[\mathrm{L}(\mathrm{H} 0)]-\mathrm{Ln}[\mathrm{L}(\mathrm{H} 1)]\}$

where $\mathrm{L}\left(\mathrm{H}_{0}\right)$ is the null hypothesis likelihood function $\left(\mathrm{H}_{0}\right)$ and $\mathrm{L}\left(\mathrm{H}_{1}\right)$ hypothesis, which is asymptotically presupposed to have mixed Chi-Square distribution.

In the Cobb-Douglas function, to determine the elasticity of the production to the inputs we used the following formula (Equation 8):

$$
E_{y, x_{k}}=\frac{\Delta \operatorname{LnE}(y)}{\Delta x_{k}}=\beta_{k}
$$

The elasticity was calculated to reach input productions (some variables such as bed, medical doctors, nurses, and other variables).
Our preliminary analysis showed that Cobb-Douglas function form $(\mathrm{LR}=7.03)$ was more appropriate for the stochastic frontier model of the hospitals under investigation in comparison to Translog form $(\mathrm{LR}=0.42)$.

Regarding the population and the statistical method of the present study, a fitted SFA model was applied and the results of the study were assessed and analyzed by Frontier 4.1 (Tim Coelli, 1996) software.

\section{Results}

Table 1 presents the descriptive statistics of the input and output variables. Figures 1 and 2 illustrate the number of resources over the study period. Figure 1 shows that the number of physicians and beds remained almost unchanged from 1999 to 2011 . In contrast, there were some fluctuations in the number of nurses and other human resources (Figure 1). The number of inpatient admissions also remained stable in this period, but as shown in Figure 2, the number of outpatient admissions increased by 32000 , from 66,000 to more than 98,000 .

The results of the stochastic frontier function estimation are presented in Table 2. The first section of the results contains a frontier function with five parameters. The lower part of Table 2 presents the variance parameters, the amount of the function of the log likelihood, and the LR test. To find an appropriate function form test for the model revealed that the Cobb-Douglas Function Form $(\mathrm{LR}=7.03, P<0.001)$ was more appropriate for the stochastic frontier model of the hospitals compared to the Translog Function ( $\mathrm{LR}=0.42, P=0.56)$.

\begin{tabular}{|c|c|c|c|c|}
\hline Variables & Mean & Standard deviation & Minimum & Maximum \\
\hline Inpatient admission & 9617.58 & 6537.31 & 926 & 27635 \\
\hline Outpatient admission & 86031.76 & 62702.51 & 3221 & 287003 \\
\hline Total number of FTE medical doctors & 69.99 & 74.09 & 10 & 295 \\
\hline Total number of FTE Nurses & 220.75 & 168.65 & 28 & 686 \\
\hline Total number of FTE other personnel & 194.78 & 187.80 & 40 & 728 \\
\hline Number of active beds & 221.21 & 155.44 & 30 & 547 \\
\hline
\end{tabular}
The inefficiency variance $\left(\sigma_{u}{ }^{2}\right)$ was estimated $0.97(\gamma)$ with

Table 1. Variable definition and descriptive statistics (Mean, SD, Min and Max)

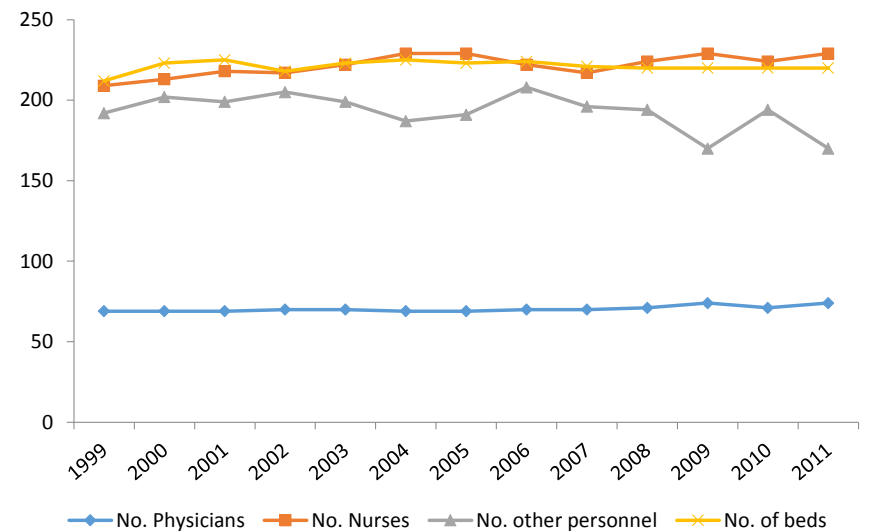

Figure 1. the trend of the number of physicians, nurses, other personnel, and beds from 1999 to 2011 in TUMS hospitals

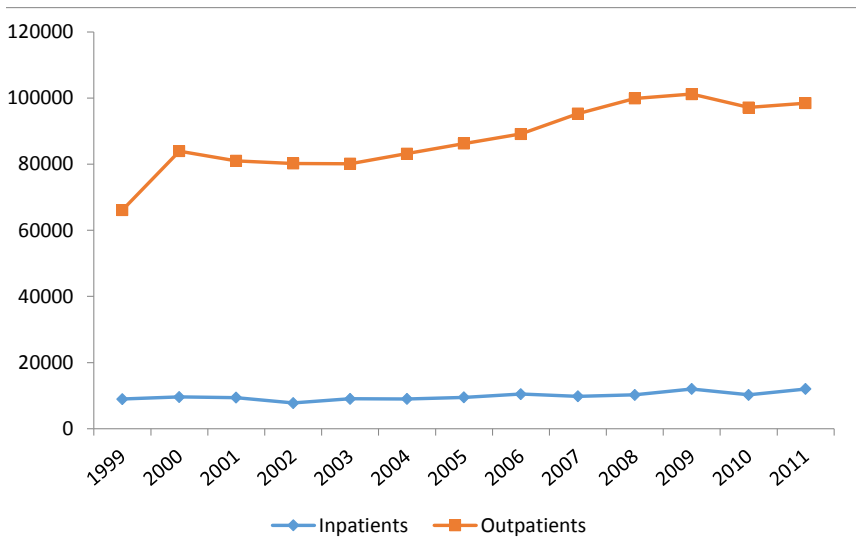

Figure 2. Variations of the number of patients both in- and out-patients from 1999 to 2011 in TUMS hospitals 
Table 2. Estimation of the parameters of the Stochastic Production Function (SPF) by the Most Likelihood (ML) method

\begin{tabular}{|c|c|c|c|c|}
\hline Variable name & Parameter & Estimation & Standard deviation & $P$-value \\
\hline \multicolumn{5}{|l|}{ Frontier function } \\
\hline Constant & $\beta_{0}$ & 2.32 & 0.57 & 4.05 \\
\hline Ln (Medical doctors) & $\beta_{1}$ & 0.22 & 0.04 & $5.34^{*}$ \\
\hline Ln (nurse) & $\beta_{2}$ & -0.34 & 0.12 & $-2.68^{*}$ \\
\hline Ln (other personnel) & $\beta_{3}$ & 0.46 & 0.12 & $3.71^{*}$ \\
\hline Ln ( active beds) & $\beta_{4}$ & -0.12 & 0.10 & -1.14 \\
\hline Ln (outpatients admission) & $\beta_{5}$ & 0.83 & 0.13 & $6.22^{*}$ \\
\hline \multicolumn{5}{|l|}{ Variance parameters } \\
\hline Sigma square & $\sigma^{2}$ & 0.81 & 0.14 & 5.71 \\
\hline Gamma & $\gamma$ & 0.97 & 0.02 & 35.51 \\
\hline
\end{tabular}

Log Likelihood $=-97.80$, LR test $=7.03,{ }^{*} P<0.05$

a standard error of 0.03 , which was highly significant with 99\% Confidence Interval (CI). These findings show that the residuals changes are considerable due to the inefficiency $\left(u_{i}\right)$. The proportion of the random error $\left(v_{i}\right)$ was about $3 \%$, which implies that the variables included in the production function were able to control random errors.

The results of the calculated elasticity are given in Table 3. As demonstrated in Table 3, the production elasticity to the outpatient visit is 0.83 , with much more elasticity in comparison with other variables. This variable shows a positive relationship with the hospital production. The sum of these elasticity coefficients is equal to 1.05 , which indicates that the production process has a Constant Return to Scale (CRS). In other words, hospitals have worked in the optimum production scales. These findings also show that except beds, other variables make statistically significant contributions to the optimum production scales (Table 2).

Table 4 illustrates the TE of hospitals affiliated to TUMS. The average efficiency of the hospitals based on this method was 0.59 , which indicated $41 \%$ potential for improvement. The mean efficiency of the TUMS's hospitals ranged from 22 to $81 \%$ without considering the severity of illness. Over the period of the study, the efficiency increased from $61 \%$ in 1999 to $71 \%$ in 2011 .

There was no full-efficient hospital (equal to 1) during the entire study period. One hospital ( $8 \%$ of the hospitals) had a TE of $0.80-1$, and other hospitals (92\% of the hospitals) had TEs less than 0.80 . The mean efficiency showed a steady

Table 3. Mean elasticity of input productions and the returns to scale by the SFA

\begin{tabular}{lll}
\hline Variable & Parameter & Elasticity \\
\hline Outpatient visit & $E_{\gamma, O V}$ & 0.83 \\
The number of FTE medical doctors & $E_{\gamma, P}$ & 0.22 \\
The number of FTE Nurses & $E_{Y, N}$ & -0.34 \\
Other personnel & $E_{\gamma, S}$ & 0.46 \\
Active beds & $E_{Y, B}$ & -0.12 \\
Returns to scale & $\mathrm{RTS}$ & 1.05 \\
\hline
\end{tabular}

decrease from 1999 until 2004, then again started to increase with some fluctuations. (Table 4).

\section{Discussion}

The results of our study showed that the average TE of hospitals affiliated with TUMS using the SFA method was 59\%, which is considerably low compared with efficiency of hospitals in other counties [See for instance Dutch hospitals (38)]. 92\% of the TUMS hospitals have TE less than $80 \%$. However a similar study, analyzing TUMS hospital efficiency, does not exist. A study using SFA method in SSOs hospitals reported the TE of 0.83 (39). The efficiency of TUMS hospitals is also lower than the pooled TE (0.85) for Iranian hospitals (18).

Around a half of the production factors are wasted during the service delivery process in the TUMS hospitals. Based on these findings, there is a great potential for efficiency improvement in the TUMS hospitals. Using the existing amount of resources, the amount of delivered outputs can be doubled, which can significantly impact patient outcomes in hospital catchment areas.

The negative elasticity of the nurses and active beds indicates a larger frequency of these variables than the other inputs such as medical doctors and other personnel. In other words, based on the principals of the economics, these variables resided in the third-phase of the production $(35,37)$. Therefore, a minor decrease in the number of FTE nurses and active beds in each hospital (with the assumption of stability in other conditions) will result in the improvement of its production power. These findings differ from some international studies $(40,41)$, which can be stemmed from the underuse of standard indices e.g. the ratio of nurses to medical doctors in recruitment decisions in TUMS hospitals (19). Findings reported by Farzianpour et al. (19) provide an evidence of excessive resources such as nurses in TUMS. More insight into excessive production factors would help policy-makers and managers to decrease costs and inefficiency. Initiatives to explore efficiency by hospital directors show their interests in efficiency improvement and would help them to appropriately allocate budget.

A study in Netherlands demonstrates that the average inefficiency for Dutch hospitals is $16 \%$, indicating approximately $€ 1.5$ billion of wasting costs for general 
Table 4. Mean efficiency scores derived from Cobb-Douglas fixed effects model for hospitals 1999-2011

\begin{tabular}{|c|c|c|c|c|c|c|c|c|c|c|c|c|c|c|}
\hline \multirow{2}{*}{ Hospital's name } & \multicolumn{13}{|c|}{ Years } & \multirow[b]{2}{*}{ Mean } \\
\hline & 1999 & 2000 & 2001 & 2002 & 2003 & 2004 & 2005 & 2006 & 2007 & 2008 & 2009 & 2010 & 2011 & \\
\hline Arash & 0.899 & 0.842 & 0.799 & 0.739 & 0.768 & 0.755 & 0.779 & 0.873 & 0.828 & 0.846 & 0.833 & 0.786 & 0.806 & 0.812 \\
\hline Valiasr & 0.911 & 0.896 & 0.927 & 0.859 & 0.860 & 0.785 & 0.713 & 0.816 & 0.683 & 0.668 & 0.708 & 0.752 & 0.754 & 0.795 \\
\hline Farabi & 0.634 & 0.754 & 0.732 & 0.732 & 0.719 & 0.652 & 0.772 & 0.885 & 0.905 & 0.913 & 0.944 & 0.845 & 0.846 & 0.795 \\
\hline Mirza Koochak Khan & 0.783 & 0.742 & 0.855 & 0.898 & 0.651 & 0.753 & 0.792 & 0.661 & 0.571 & 0.533 & 0.705 & 0.794 & 0.722 & 0.728 \\
\hline Sina & 0.536 & 0.866 & 0.766 & 0.674 & 0.862 & 0.786 & 0.861 & 0.485 & 0.573 & 0.603 & 0.691 & 0.786 & 0.792 & 0.714 \\
\hline Ziaeeyan & 0.677 & 0.614 & 0.620 & 0.535 & 0.594 & 0.551 & 0.583 & 0.657 & 0.665 & 0.669 & 0.661 & 0.791 & 0.568 & 0.630 \\
\hline Imam Khomeini & 0.507 & 0.499 & 0.473 & 0.470 & 0.586 & 0.576 & 0.647 & 0.703 & 0.690 & 0.691 & 0.702 & 0.723 & 0.713 & 0.614 \\
\hline Bahrami & 0.543 & 0.663 & 0.498 & 0.147 & 0.512 & 0.450 & 0.478 & 0.545 & 0.501 & 0.555 & 0.592 & 0.727 & 0.793 & 0.539 \\
\hline Children Hospital & 0.576 & 0.364 & 0.369 & 0.412 & 0.417 & 0.355 & 0.348 & 0.482 & 0.485 & 0.587 & 0.717 & 0.731 & 0.809 & 0.512 \\
\hline Razi & 0.264 & 0.218 & 0.234 & 0.228 & 0.258 & 0.229 & 0.206 & 0.214 & 0.194 & 0.204 & 0.292 & 0.634 & 0.696 & 0.298 \\
\hline Roozbeh & 0.171 & 0.147 & 0.141 & 0.149 & 0.144 & 0.150 & 0.183 & 0.211 & 0.198 & 0.211 & 0.171 & 0.537 & 0.558 & 0.229 \\
\hline Mean & 0.610 & 0.585 & 0.565 & 0.520 & 0.562 & 0.534 & 0.560 & 0.586 & 0.577 & 0.570 & 0.625 & 0.721 & 0.714 & 0.594 \\
\hline
\end{tabular}

hospitals through their inefficiency every year (38). On the other hand, due to inefficiency of health service providing units and considering limitations of the resources, policymakers are highly motivated to better plan and allocate resources to promote service providing, paying more attention to healthcare, prevention, educational affairs, and human resources.

National and international benchmarking of hospital performance including hospitals with different organizational forms might help to provide more insights in the sources of hospital inefficiency (38). At a smaller scale, benchmarking the efficiency of hospital units contributes to performance improvements (19).

Researchers engaged in the field of hospital efficiency measurement discuss the relative usage of the methods used. Reviewing the available hospital efficiency studies using frontier-based techniques in developing countries has revealed that, although the choice of measurement methods in hospital efficiency assessment has been extensively researched, only few authors have presented a framework to determine variables reflecting different hospital functions, the quality of the process of care and the effectiveness of hospital services. This would indirectly show that the main objective of a hospital and its full range of functions in efficiency measurement are vaguely understood. This can be deduced from the fact that Afzali et al. (2) stated that this can be resulted from this fact that several researches had selected various sets of variables and there was not straightforward recommendations for selecting variables. One theory for such inconsistencies is the lack of conceptual clarity for selecting the most appropriate variables for measuring hospital efficiency (2).

\section{Limitations}

Our study has some limitations. First of all, case mixed index is not considered in efficiency estimations. To alleviate this, we used inpatient admissions instead of a hospital output. Second, the SFA method allows to select only one output; this would cause the omission of important outputs. Furthermore, patient perspective is not considered when selecting output variables in this efficiency analysis. We were not able to measure and collect appropriate data regarding the health outcomes, patient safety, mortality rates, the quality of care, and patient satisfaction as outputs. Because of this restricted validity and reliability of data collection in Iranian hospitals, Kiadaliri et al. (18) recommended a standard approach to improve data collection and process in Iranian hospital databases, which may have an impact on improving the value of studies in this context.

\section{Acknowledgments}

The authors would like to appreciate all hospitals' administrators for their cooperation in data collection. This study was financially supported by Tehran University of Medical Sciences (TUMS) by the grant number 86/04/27/6621.

\section{Ethical issues}

This research was approved by ethics committee of Tehran University of Medical Sciences (TUMS).

\section{Competing interests}

The authors declare that they have no competing interests.

Authors' contributions

$\mathrm{RG}$ and $\mathrm{AP}$ designed the research; RG, AP, MS, RA, and JM contributed to searching the literature, analyzing the results and its interpretation; MS, RG, and AP drafted the initial manuscript. MS, RG, and MM mainly and other co-authors in some minor parts answered to the reviewers' remarks and recommendations. All authors read and approved the final manuscript.

\section{Authors' affiliations}

${ }^{1}$ Department of Health Management and Economics, School of Public Health, Tehran University of Medical Sciences, Tehran, Iran. ${ }^{2}$ Research Center for Modeling in Health, Kerman University of Medical Sciences, Institute for Futures studies in Health, Kerman, Iran. IInstitute of Health Policy and Management, Erasmus University Rotterdam, Rotterdam, Netherlands.

\section{References}

1. McKee M, Healy J. Hospitals in a Changing Europe. Open University Press: Philadelphia; 2002. 
2. Afzali HHA, Moss JR, Mahmood MA. A conceptual framework for selecting the most appropriate variables for measuring hospital efficiency with a focus on Iranian public hospitals. Health Serv Manage Res 2009; 22: 81. doi: 10.1258/hsmr.2008.008020

3. World Bank. Iran National Health Accounts. World Bank, 2001.

4. de Castro Lobo M, Ozcan Y, da Silva AM, Lins ME, Fiszman R. Financing reform and productivity change in Brazilian teaching hospitals: Malmquist approach. Central Eur J Oper Res 2010; 18: 141-52. doi: 10.1007/s10100-009-0097-z

5. Salek-Ardakani S, Smooha G, de Boer J, Sebire NJ, Morrow M, Rainis L, et al. ERG is a megakaryocytic oncogene. Cancer Res 2009; 69: 4665-73. doi: 10.1158/0008-5472.CAN-09-0075

6. Yaisawarng S. Performance measurement and resource allocation. In Fox K J, (editor). Efficiency in the Public Sector. Boston: Kluwer Academic Publishers; 2002.

7. Duckett SJ. The Australian Health Care System. Melbourne: Oxford University Press; 2003.

8. Sherman D. Hospital efficiency measurement and evaluation. Med Care 1984; 22: 922-38. doi: 10.1097/00005650-19841000000005

9. Farzianpour F, Arab M, Fouroshani AR, Rashidian A. Evaluation of international standards of Quality improvement and Patient Safety (QPS) in hospitals of Tehran University of Medical Sciences (TUMS) from the Managers' Point of View. World Applied Sci J 2011; 15: 647-53.

10. Farzianpour F, Aghababa S, Delgoshaei B, Haghgoo M. Performance evaluation a teaching hospital affiliated to Tehran University of medical sciences based on baldrige excellence model. American Journal of Economics and Business Administration 2011; 3: 277-81. doi: 10.3844/ ajebasp.2011.272.276

11. Flokou A, Kontodimopoulos N, Niakas D. Employing post-DEA cross-evaluation and cluster analysis in a sample of greek NHS hospitals. J Med Syst 2011; 35: 1001-14. doi: 10.1007/s10916010-9533-9

12. Barnum DT, Walton SM, Shields KL, Schumock GT. Measuring hospital efficiency with data envelopment analysis: Nonsubstitutable vs. Substitutable Inputs and Outputs. J Med Syst 2009; 35: 1393-401. doi: 10.1007/s10916-009-9416-0

13. O'Neill L. Multifactor efficiency in DEA with an application to urban hospitals. Health Care Manag Sci 1998; 1: 19-27.

14. Chirikos TN, Sear AM. Measuring hospital efficiency: A comparison of two approaches. Health Serv Res 2000; 34: 1389-408.

15. Rosko M. Cost Efficiency Of Us Hospitals: A Stochastic Frontier Approach. Health Econ 2001; 10: 539-51. doi: 10.1002/hec.607

16. Kirigia JM, Emrouznejad A, Sambo LG. Measurement of technical efficiency of public hospitals in Kenya: Using data envelopment analysis. J Med Syst 2002; 26: 39-45. doi: 10.1023/B:JOMS.0000023298.31972.c9

17. Ramanathan R. Operations assessment of hospitals in the Sultanate of Oman. Int J Oper Prod Man 2005; 25: 39-54. doi: 10.1108/01443570510572231

18. Kiadaliri A, Jafari M, Gerdtham Ug. Frontier-based techniques in measuring hospital efficiency in Iran: a systematic review and meta-regression analysis. BMC Health Serv Res 2013; 13: 312. doi: 10.1186/1472-6963-13-312

19. Farzianpour F, Hosseini S, Amali T, Hosseini S, Hosseini S, Hosseini SS. The Evaluation of Relative Efficiency of Teaching Hospitals. American Journal of Applied Sciences 2012; 9: 392-8.

20. Sheikhzadeh Y, Roudsari AV, Vahidi RG, Emrouznejad A, Dastgiri S. Public and Private Hospital Services Reform Using Data Envelopment Analysis to Measure Technical, Scale, Allocative, and Cost Efficiencies. Health Promot Perspect 2012; 2: 28-41.

21. Hatam N. The role of Data Envelopment Analysis (DEA) pattern in the efficiency of social security hospitals in Iran. Iranian Red
Crescent Med J 2008; 10: 211-7.

22. Shahhoseini $R$, Tofighi $S$, Jaafaripooyan E, Safiaryan R. Hospitals Efficiency measurement in developing countries: application of data envelopment analysis for Iranian. Health Serv Manage Res 2011; 24: 75. doi: 10.1258/hsmr.2010.010017

23. Haji Ali Afzali H, Moss JR, Mahmood MA. Exploring health professionals' perspectives on factors affecting Iranian hospital efficiency and suggestions for improvement Int $J$ Health Plann Mgmt 2011; 26. doi: 10.1002/hpm.1035

24. Al-Shammari M. A multi-criteria data envelopment analysis model for measuring the productive efficiency of hospitals. Int J Oper Produ Manage 1999; 19: 879-91. doi: 10.1108/01443579910280205

25. Farrell MJ. The Measurement of Productive Efficiency. Journal of the Royal Statistical Society 1957; 120: 253-81. doi: $10.2307 / 2343100$

26. Prochazkova J. Efficiency of Hospitals in The Czech Republic: DEA \& SFA Applications [Doctoral Thesis]. Prague: Charles University, Faculty of Social Sciences; 2011.

27. Newhouse J. Fronteir estimation: How useful a tool for health economics? J Health Econ 1994; 13: 317-22.

28. Grosskopf S, Valdmanis V. Measuring hospital performance: A non-parametric approach. J Health Econ 1987; 6: 89-107. doi: 10.1016/0167-6296(87)90001-4

29. Frohloff A. Cost and Technical Efficiency of German Hospitals: Does Ownership Matter? Health Econ 2008; 17: 1057-71. doi: 10.1002/hec.1388

30. Lin LC, Tseng LA. Application of DEA and SFA on the Measurement of Operating Efficiencies for 27 International Container Ports. Proceedings of the Eastern Asia Society for Transportation Studies 2005; 5: 592-607.

31. Ravangard R, Hatam N, Teimourizad A, Jafari A. Factors affecting the technical efficiency of health systems: A case study of Economic Cooperation Organization (ECO) countries (200410). Int J Health Policy Manag 2014; 2: 1-7. doi: 10.15171/ ijhpm.2014.60

32. Battese GE, Coelli TJ. A model for technical inefficiency effects in a stochastic frontier production function for panel data. Empirical Economics 1995; 20: 325-32. doi: 10.1007/bf01205442

33. Ozcan YA, Luke RD, Haksever C. Ownership and organizational performance: A comparison of technical efficiency across hospital types. Med Care 1992; 30: 780-94. doi: 10.1097/00005650199209000-00003

34. Hofmarcher MM, Paterson I, Riedel M. Measuring hospital efficiency in Austria: A DEA approach. Health Care Manag Sci 2002; 5: 7-14.

35. Schmidt P, Sickles RC. Production Frontiers and Panel Data. Journal of Business and Economic Statistics 1984; 4: 367-74.

36. Gannon B. Testing for variation in technical efficiency of hospitals in Ireland. Economic and Social Review 2005; 36: 273-94.

37. Meussen W, van den Brock J. Efficiency Estimation from CobbDouglas Production Functions with Composed Error. Int Econ Rev (Philadelphia) 1977; 18: 435-44. doi: 10.2307/2525757

38. Ludwig M. Efficiency of Dutch hospitals [Doctoral Thesis]. Netherlands: Maastricht University; 2008.

39. Hatam N, Javanbakht M, Pourmohammadi K. [Measure technical efficiency of Iranian social security hospitals by using data envelopment analysis and stochastic frontier analysis in the years 2006-2008]. Shiraz: Shiraz University of Medical Sciences; 2009.

40. Sahin I, Ozcan Y. Public sector hospital efficiency for provincial markets in Turkey. J Med Syst 2000; 24: 307-20.

41. Chang $\mathrm{H}$, Chang WJ, Das $\mathrm{S}$, Li SH. Health care regulation and the operating efficiency of hospitals: Evidence fro Taiwan. Journal of Accounting and Public Policy 2004; 23: 483-510. doi: 10.1016/j.jaccpubpol.2004.10.004 


\section{Key Messages}

\section{Implications for policy makers}

The implications of this research for policy-makers are as follows.

- Efficiency scores provide insight into mismanagement of available resources. A lower efficiency rate, as reported in this study, warrants the top management in TUMS to take serious actions and to bring the management of hospitals at the top of agenda for better resource management. Interventions to improve the quality of management in the hospitals studied could help to improve efficiency.

- Given that the majority of hospital administrators have little knowledge on costs and financial management of hospitals, inefficient service delivery is not unexpected. We suggest human resource policies and strategic decisions should be altered. Further, interventions for management improvement may focus on cost awareness and increased authority and responsibility of hospital management teams for better financial management.

- Standard indices for human resources are general measures for resource allocations that may not take local concerns into consideration. Efficiency analysis may contribute to determine an efficient combination of resources and local concerns instead of relying on the standard indices. Therefore, an efficiency analysis can be used as a review tool to assess decisions regarding human and other resources in monetary terms and to modify policies accordingly.

- Efficiency dilemma represents serious problems in designing service processes in the studied hospitals. Therefore, process improvement tools need to be applied while taking patient perspective, i.e. quality of life and satisfaction, into considerations.

\section{Implications for public}

Health service providers are under a tight pressure by increasing patient demands. Patients ask for more services e.g. inpatient and outpatient admissions to hospitals given the aging of populations and a greater burden of chronic diseases. Inefficient service delivery, as the case in the TUMS hospitals, decreases the number of outputs while more services can be provided. Given the rises in demands, inefficient service provisioning results in longer waiting times and more unmet demands. Therefore, efficiency of the hospitals directly affects the convenience and indirectly affects health outcomes and quality of life by limited access to services. Altogether, the efficiency of services affects satisfaction with services as this is mostly defined by the quality of care as well as patient health and quality of life.

Efficiency improvement also contributes to allocative efficiency in healthcare delivery systems by saving money and scare resources. The saved resources can be directed towards more cost-effective interventions such as community education and primary preventions in turn decreasing the demands for hospital services and more monetary resources. 